\title{
FREQUENCY AND ANTIMICROBI AL SUSCEPTIBILITY PATTERN OF GRAM-NEGATIVE BACILLI ISOLATED FROM URINE SPECIMENS AT A TERTIARY CARE SETTING
}

\author{
Aamir Hussain ${ }^{1}$, Ihsan Ullah $^{2}$, Humera Adeeb ${ }^{3}$, Mubarak Zeb $^{4}$
}

\section{$\underline{\text { ABSTRACT: }}$}

\section{OBJECTIVES:}

To find out the frequency and pattern of conventional antibiotic su sceptibility of gram-negative bacilli cultured from urine specimens of patients at a tertiary care setting.

\section{METHODOLOGY:}

This study was conducted at the Microbiology Department of Combined Military Hospital Multan from June 2016 to May 2017. The data in this retrospective descriptive study was collected from urine culture records of the Microbiology Department, CMH Multan. Only those urine specimens who revealed positive gram-negative bacilli cultures were included in the study. Drug susceptibility patterns of these isolates were recorded against routinely used antibiotics (e.g. Nitrofurantoin, Imipenem, Sulbactum-cefoperazone, Gentamicin and Ciprofloxacin) and evaluated accordingly.

\section{RESULTS:}

A total of 1703 urine specimens were submitted for culture and antibiotics susceptibility testing during the period of study. A total of 128 specimens showed growth of gram-negative rods. Imipenem (95\% sensitivity), Sulbactam- Cefoperazone (88\% sensitivity) and Nitrofurantoin (87\% sensitivity) were highly effective antibiotics against the cultured gram-negative bacilli in the study.

\section{CONCLUSION:}

This study showed that E. coli is the commonest cause of urinary tract infection (UTIs), followed by Klebsiella and Enterobacter species among gram-negative bacilli in our set up. In-vitro efficacy of Imipenem, SulbactamCefoperazone and Nitrofurantoin was found to be the highest against these gram-negative bacilli as compared to other antimicrobials. On the contrary, in-vitro efficacy of ciprofloxacin and gentamycin was found to be extremely low.

KEYWORDS: Antimicrobial Susceptibility, Escherichia Coli, Gram-Negative Bacilli, Urine Culture, Urinary Tract Infection

How to cite this article:

Hussain A, Ullah I, Adeeb H, Zeb M. Frequency and Antimicrobial Susceptibility Pattern of Gram-Negative Bacilli Isolated from Urine Specimens at A Tertiary Care Setting. J Gandhara Med Dent Sci. 2022;9(1): 15-19

https://doi.org/10.37762/jgmds.9-1.126 


\section{Correspondence:}

${ }^{2}$ Ihsan Ullah, Associate Professor, Khyber Medical University, Peshawar.

(8) $+92-313-9558883$

叉: drihsan.ibms@kmu.edu.pk

${ }^{1}$ Lieutenant Colonel, Combined military Hospital, Multan

${ }^{3}$ Trainee Community Medicine, Khyber Medical College,

Peshawar

${ }^{4}$ Senior Medical Specialist, District Health System, Peshawar

\section{INTRODUCTION:}

Urinary tract infections (UTIs) are one of the most common bacterial infectious diseases encountered in clinical practice. UTIs include microbial infection of the urinary tract including urinary bladder and urethra. Females are more frequently affected by UTI due to their short urethra length. An estimated 150 million cases of UTIs are reported worldwide annually with the highest incidence in the developing world ${ }^{1,2}$. These infections account for a significant morbidity and high medical costs, on part of patients as well as institutions/hospitals, especially in elderly males and females of all age groups ${ }^{3}$. Clinically, patients suffering from UTIs may present with a wide variety of symptoms. Most of the UTIs are asymptomatic or may start with some form of mild symptoms and then gradually increase in severity ending with cystitis leading to severe septecemia ${ }^{4}$. Urinary tract infections are most commonly caused by gram-negative bacteria, but gram-positive bacteria may also cause it in certain conditions. Few cases of UTIs are also caused by certain medically important fungi, which are commonly detected by their non-responsive nature to antibiotics. Gram-negative bacteria are the most common bacterial pathogens in such infections where Escherichia coli being the major etiological agent among gram-negative bacteria, followed by Klebsiella pneumonia, ${ }^{5,6}$ Escherichia coli, an important pathogen alone accounts for approximately $80-90 \%$ of UTI. Around $30-50 \%$ of community acquired and nosocomial urinary tract infections are caused by E.coli, which shows the importance of this pathogen ${ }^{7}$. Patients presenting with symptoms of urinary tract infections are usually prescribed empirical antibiotic treatment in our set up. Culture and sensitivity testing is usually not prescribed as it takes a few days to show the causative organism and its antibacterial susceptibility results. The empirical antibiotic prescription leads to development of resistance in these pathogens ${ }^{8,9}$. Recent data suggest an increasing trend of antibiotic resistance among uropathogens isolated from urine culture ${ }^{10}$. The antibiotic susceptibility pattern of uropathogens, especially gram-negative rods also vary according to different healthcare settings and geographical locations ${ }^{11,12}$. Not much work has been done in this regard in the southern Punjab region of Pakistan. In the present study, we report the prevalence of gram negative bacilli among pathogens causing urinary tract infections along with their antimicrobial susceptibility profile, isolated from both indoor and outdoor patients of this tertiary care hospital of southern Punjab region of Pakistan.

\section{METHODOLOGY:}

Mid-stream urine samples were collected from all patients in sterile wide mouthed containers under aseptic conditions. Urine specimens were then inoculated on cysteine lactose electrolyte deficient (CLED) agar using a semi-quantitative strip method (Abtek Biologicals Ltd, Liverpool) and applying $0.2 \mu \mathrm{l}$ per strip. The inoculated plates were then aerobically incubated at $37^{\circ} \mathrm{C}$ for $18-24$ hours. Gram-negative rods (more than 20 colonies were considered significant) were provisionally identified by colony morphology and Gram's staining. Biochemical reactions were used for the final identification of bacterial species. For antimicrobial susceptibility testing, Mueller-Hinton agar (Oxoid, UK) was carefully inoculated with the test organism (0.5 McFarland standards), and a semi-confluent growth was obtained. Then appropriate antibiotic discs were applied on this $\mathrm{MH}$ Agar. Following overnight incubation in air at $35^{\circ} \mathrm{C} \pm 2$, zone diameters were measured and interpreted as per CLSI guidelines ${ }^{13}$. The antibiotic discs and their concentration used were Nitrofurantoin $\quad(300 \mu \mathrm{g})$, Imipenem $(10 \mu \mathrm{g})$, Sulbactum-cefoperazone (30/10) $\mu \mathrm{g}$, Gentamicin $(30 \mu \mathrm{g})$, and Ciprofloxacin $(5 \mu \mathrm{g})$. Bacterial isolates were then classified as resistant, intermediate sensitivity or totally sensitive to the above antibiotics based on CLSI guidelines.

\section{RESULTS:}

Out of 1703 urine specimens submitted for culture and drug susceptibility, 128 (7.51\%) yielded significant growth of gram-negative bacilli and E.coli was the most frequent one. E.coli was found in more than half of all the isolated gram-negative bacilli. The frequencies of all gram-negative bacilli cultured from these samples are shown in the Figure1. 


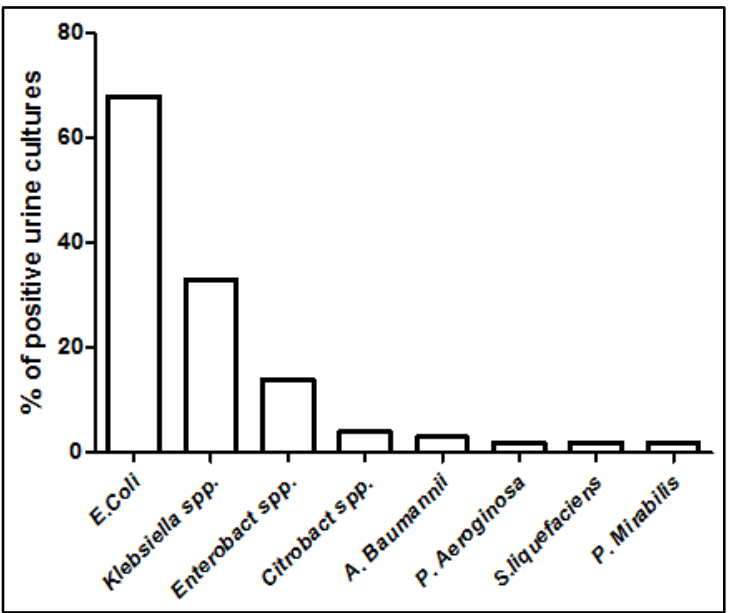

Figure1: Frequency of Gram Negative Bacilli Cultured from Urine Specimens $(n=128)$

Table 1: Antibiotic Susceptibility Profile of Gram-Negative Bacilli (n=128)

\begin{tabular}{|l|c|c|c|c|c|}
\hline \multicolumn{1}{|c|}{ Gram Negative Bacilli } & $\begin{array}{c}\text { Imepenam } \\
\text { (Sensitive) } \\
\mathbf{\%}\end{array}$ & $\begin{array}{c}\text { Nitrofurantoin } \\
\text { (Sensitive) } \\
\mathbf{\%}\end{array}$ & $\begin{array}{c}\text { Ciprofloxacin } \\
\text { (Sensitive) } \\
\mathbf{\%}\end{array}$ & $\begin{array}{c}\text { Sulbactam- } \\
\text { Cefoperazone } \\
\text { (Sensitive) \% }\end{array}$ & $\begin{array}{c}\text { Gentamycin } \\
\text { (Sensitive) } \\
\%\end{array}$ \\
\hline E. Coli & 68 & 64 & 38 & 63 & 42 \\
\hline Klebsiella Spp. & 31 & 33 & 20 & 29 & 21 \\
\hline Enterobacter Spp. & 11 & 11 & 2 & 10 & 5 \\
\hline Citrobacter Spp. & 3 & 4 & 2 & 2 & 1 \\
\hline Acinetobacter Baumannii & 3 & 1 & - & 2 & 1 \\
\hline Pseudomonas Aeruginosa & 1 & 1 & - & 1 & - \\
\hline Serratia Liquefaciens & 2 & - & 1 & 1 & - \\
\hline Proteus Mirabilis & 2 & - & $63(49 \%)$ & $112(88 \%)$ & $70(55 \%)$ \\
\hline Total & $121(95 \%)$ & $111(87 \%)$ & & & \\
\hline
\end{tabular}

\section{DISCUSSION:}

Increasing antibiotic resistance is a serious health concern in the present daytime. These resistant bacteria not only increase the cost of treatment for both patients as well as hospitals/institutions but are also a leading cause of treatment failures. The findings of this study have shown that more than half $(>53 \%)$ of all the culture positive gramnegative isolates were identified as E.coli. Literature search about isolation of E.coli as uropathogens has shown that it is different for different regions of the world. It has shown to vary from $25 \%$ (which was shown in a Nigerian study) up to $81 \%$, which was reported in a study from Nepa ${ }^{14,15}$. Frequency of isolation of E.coli as uropathogens in our study is almost close to the frequency reported from other local and regional studies. A study from Khyber Teaching Hospital Peshawar, conducted in 2002, showed that $57 \%$ of all their isolates from culture of urine specimens were E.coli ${ }^{16}$. Similarly another study from Ayub Medical College Abbottabad showed that $77 \%$ of all urine cultures revealed E.coli ${ }^{17}$. Two different studies conducted at the Armed Forces Institute of Pathology Rawalpindi, have shown frequency of isolation of E.coli as $52 \%$ and $63 \%{ }^{18}$. Another study from India has reported $62 \%$ of their uropathogens as E.coli ${ }^{19}$. Contrary to these findings, two different studies conducted in India and Nepal in 2009 reported the isolation rate of E.coli to be $36 \%$ and $25 \%$ of the total culture positive urine samples from two centers respectively ${ }^{20,21}$. Klebsiella and Enterobacter species were the next most commonly isolated gram-negative bacteria. These findings were consistent with the reports from other studies as well ${ }^{22,23}$. The results our study has revealed that imipenem, Sulbactum-cefoperazone and Nitrofurantoin are the most effective drugs against gram negative pathogens causing urinary tract infections, as $95 \%$ isolates were susceptible to imipenem while more than $85 \%$ of the isolates were sensitive to Sulbactum-cefoperazone and nitrofurantoin. Similar susceptibility profile for imipenem has been reported from a study conducted in India, where $95 \%$ of urinary isolates were susceptible to carbapenems. Nitrofurantoin 
has also shown a similar susceptibility pattern in two previous studies conducted in the Armed Forces Institute of Pathology in 2004 and 2010. According to these two studies $88 \%$ and $87 \%$ of E.coli were susceptible to nitrofurantoin respectively ${ }^{18,24}$. Sensitivity pattern of organisms against Sulbactam-Cefoperazone was $88 \%$. Similar sensitivity profile was also reported from a study conducted in India, where $93 \%$ of the E.coli isolates were found to be sensitive to this drug ${ }^{19}$. On the contrary, in vitro susceptibility results of urinary gram-negative pathogens against Gentamycin and ciprofloxacin were quite low, as almost $50 \%$ of all the isolates were sensitive to both these antibiotics. As regards the susceptibility results for ciprofloxacin, our isolates were less resistant compared to another study conducted in Peshawar in 2005/2006 where only $28 \%$ of E.coli isolated were susceptible to this compound ${ }^{25}$. As not much clinical details were provided with the urine specimens submitted for culture and antibiotic susceptibility testing, so clinical correlation could not be done for the in vitro susceptibility test results. However this important laboratory data shall be quite helpful in formulating empirical treatment options for urinary tract infections, in this part of the world. Other laboratories /diagnostic centers should also publish their data regarding urinary pathogens which will help clinicians in recommending empirical treatment for urinary tract infections.

\section{CONCLUSION:}

E.coli is the most common gram-negative bacillus causing urinary tract infections (UTIs) in our set up. Although these gram negative urinary pathogens have developed resistance against certain routinely used antibiotics like Ciprofloxacin but still show more than $80 \%$ sensitivity to antibiotics like Nitrofurantoin and Carbapenems (imipenem). Carbapenems should be considered as a drug of choice in these infections because these pathogens are $95 \%$ susceptible to it.

\section{CONFLICT OF INTEREST: None}

\section{FUNDING SOURCES: None}

\section{REFERENCES:}

1. Venkatesh RK, Prabhu MM, Nandakumar $\mathrm{K}$, Pai KS. Urinary tract infection treatment pattern of elderly patients in a tertiary hospital setup in South India: a prospective study. J Young Pharm. 2016;8(2):108-13.
2. Mihankhah A, Khoshbakht R, Raeisi M, Raeisi V. Prevalence and antibiotic resistance pattern of bacteria isolated from urinary tract infections in Northern Iran. J Res Med Sci. 2017;22:108.

3. Reu CE, Volanski W, Prediger KC, Picheth G, Fadel-Picheth CM. Epidemiology of pathogens causing urinary tract infections in an urban community in southern Brazil. Braz J Infect Dis. 2018;22:505-7.

4. Naveen R, Mathai E, Some virulance characteristics of uropathgenic escherichia coli in different patients groups. Indian J Med Res. 2015:122:143-7.

5. Yilmaz N, Ağuş N, Bayram A, Şamlıoğlu P, Şirin MC, Derici YK, et al. Antimicrobial susceptibilities of escherichia coli isolates as agents of community-acquired urinary tract infection (2008-2014). Turk J Urol. 2016;42(1):32.

6. Afrugh $\mathrm{P}$, Mardaneh J, Kaidani A, Serajian AA, Abbasi P, Yahyavi M. Distribution and antimicrobial susceptibility pattern of gram negative bacteria causing urinary tract infection (UTI) and detection New Delhi Metallobeta-lactamase-1 (NDM-1) producing isolates in Ahwaz. Iran South Med J. 2016;19(1):15-26.

7. Jhang JF, Kuo HC. Recent advances in recurrent urinary tract infection from pathogenesis and biomarkers to prevention. Tzu-Chi Med J. 2017;29(3):131.

8. Muhammad A, Khan SN, Ali N, Rehman MU, Ali I. Prevalence and antibiotic susceptibility pattern of uropathogens in outpatients at a tertiary care hospital. New Microbes New Infect. 2020;36:100716.

9. Terlizzi ME, Gribaudo G, Maffei ME. UroPathogenic Escherichia coli (UPEC) infections: virulence factors, bladder responses, antibiotic, and non-antibiotic antimicrobial strategies. Front Microbiol. 2017;8:1566.

10. Byron JK. Urinary tract infection. Vet Clin North Am Small Anim Pract. 2019;49(2):211-21.

11. Rudramurthy KG, Kumaran R, Geetha RK. Etiology and antimicrobial susceptibility pattern of bacterial agents from urinary tract infection in a tertiary care centre. Int J Sci Stud. 2015;2:125-7. 
12. Nigussie D, Amsalu A. Prevalence of uropathogen and their antibiotic resistance pattern among diabetic patients. Turk J Urol. 2017;43(1):85.

13. Humphries RM, Hindler J, Jane Ferraro M, Mathers A. Twenty-first century cures act and antimicrobial susceptibility testing: clinical implications in the era of multidrug resistance. Clin Infect Dis. 2018;67(7):1132-8.

14. Abdu A, Kachallah M, Bolus DY. Antibiotic susceptibility patterns of uropathogenic escherichia coli among patients with urinary tract infections in a tertiary care hospital in Maiduguri, North Eastern, Nigeria. J Biosci Biotechnol Discov. 2018;3:14-24.

15. Dehbanipour R, Rastaghi S, Sedighi M, Maleki N, Faghri J. High prevalence of multidrug-resistance uropathogenic escherichia coli strains, Isfahan, Iran. J Nat Sci Biol Med. 2016;7(1):22.

16. Shrestha LB, Baral R, Poudel P, Khanal B. Clinical, etiological and antimicrobial susceptibility profile of pediatric urinary tract infections in a tertiary care hospital of Nepal. BMC Pediatr. 2019;19(1):1-8.

17. Rabbee MF, Begum MK, Islam MJ, Chowdhury PA, Chowdhury OA, Zohora FT, et al. Multidrug resistance phenotype and plasmid profiling of escherichia coli isolates causing urinary tract infections in northeast part of Bangladesh. Microbiol Res J Int. 2016:1-10.

18. Rahim MA, Mitra P, Haque A, Zaman S, Samad T, Haque WM, et al. Urinary tract infection due to extended-spectrum betalactamase producing organisms is a risk factor for acute kidney injury among patients with type-2 diabetes mellitus. J Med. 2018;19(1):40-3.
19. Khatri R, Tripathi H. Current scenario of antimicrobial resistance pattern of uropathogenic escherichia coli in a Tertiary Care Hospital at Jaipur, Rajasthan. Int J Sci Res. 2020;9(9).

20. Rani KL, Ramaswamy R. Isolation and antibiotic sensitivity pattern of citrobacter species with ESBL and AmpC detection at tertiary care hospital, Bangalore. J Evol Med Dent Sci. 2016;5(30):1553-7.

21. Derese B, Kedir H, Teklemariam Z, Weldegebreal F, Balakrishnan S. Bacterial profile of urinary tract infection and antimicrobial susceptibility pattern among pregnant women attending at Antenatal Clinic in Dil Chora Referral Hospital, Dire Dawa, Eastern Ethiopia. Ther Clin Risk Manage. 2016;12:251.

22. Gajdács M. Epidemiology and antibiotic resistance trends of pantoea species in a tertiary-care teaching hospital: a 12-year retrospective study. Dev Health Sci. 2019;2(3):72-5.

23. Bhayani P, Rawekar R, Bawankule S, Kumar S, Acharya S, Gaidhane A, et al. Profile of urinary tract infection in a rural tertiary care hospital: two-year crosssectional study. J Datta Meghe Inst Med Sci Univ. 2019;14(1):22.

24. Keepers TR, Gomez M, Celeri C, Krause KM, Biek D, Critchley I. Fosfomycin and comparator activity against select enterobacteriaceae, pseudomonas, and enterococcus urinary tract infection isolates from the United States in 2012. Infect Dis Ther. 2017;6(2):233-43.

25. Ullah F, Malik SA, Ahmen J. Antibiotic susceptibility pattern and ESBL prevalence in nosocomical escherichia coli from urinary tract infractions in Pakistan. Afr J Biotechnol. 2017;8(16):3921-6.

\section{CONTRIBUTORS}

1. Aamir Hussain - Concept \& Design; Data Acquisition; Data Analysis/Interpretation; Drafting Manuscript

2. Ihsan Ullah - Concept \& Design; Data Analysis/Interpretation; Drafting Manuscript; Critical Revision; Supervision; Final Approval

3. Humera Adeeb - Data Analysis/Interpretation; Drafting Manuscript; Critical Revision; Final Approval

4. Mubarak Zeb - Drafting Manuscript; Critical Revision; Final Approval

LICENSE: JGMDS publishes its articles under a Creative Commons Attribution Non-Commercial Share-Alike license (CC-BY-NC-SA 4.0). COPYRIGHTS: Authors retain the rights without any restrietions to freely download, print, share and disseminate the article for any lawful purpose. It includes scholarly networks such as Research Gate, Google Scholar, LinkedIn, Academia.edu, Twitter, and other academic or professional networking sites. 